\title{
Global-scale climate impact functions: the relationship between climate forcing and impact
}

\author{
N. W. Arnell • S. Brown • S. N. Gosling • J. Hinkel • \\ C. Huntingford • B. Lloyd-Hughes • J. A. Lowe • \\ T. Osborn • R. J. Nicholls • P. Zelazowski
}

Received: 30 January 2013 / Accepted: 10 December 2013 /Published online: 21 January 2014

C) The Author(s) 2014. This article is published with open access at Springerlink.com

\begin{abstract}
Although there is a strong policy interest in the impacts of climate change corresponding to different degrees of climate change, there is so far little consistent empirical evidence of the relationship between climate forcing and impact. This is because the vast majority of impact assessments use emissions-based scenarios with associated socio-economic assumptions, and it is not feasible to infer impacts at other temperature changes by interpolation. This paper presents an assessment of the global-scale impacts of climate change in 2050
\end{abstract}

This article is part of a Special Issue on "The QUEST-GSI Project" edited by Nigel Arnell.

Electronic supplementary material The online version of this article (doi:10.1007/s10584-013-1034-7) contains supplementary material, which is available to authorized users.

N. W. Arnell $(\bowtie) \cdot$ B. Lloyd-Hughes

Walker Institute for Climate System Research, University of Reading, Reading, UK

e-mail: n.w.arnell@reading.ac.uk

S. Brown · R. J. Nicholls

Faculty of Engineering and the Environment and Tyndall Centre for Climate Change Research, University of Southampton, Southampton, UK

S. N. Gosling

School of Geography, University of Nottingham, Nottingham, UK

J. Hinkel

Global Climate Forum, Berlin, Germany

C. Huntingford

Centre for Ecology and Hydrology, Wallingford, UK

J. A. Lowe

Department of Meteorology, Met Office Hadley Centre, University of Reading, Exeter, UK

T. Osborn

Climatic Research Unit, University of East Anglia, Norwich, UK

P. Zelazowski

Environmental Change Institute, University of Oxford, Oxford, UK 
corresponding to defined increases in global mean temperature, using spatially-explicit impacts models representing impacts in the water resources, river flooding, coastal, agriculture, ecosystem and built environment sectors. Pattern-scaling is used to construct climate scenarios associated with specific changes in global mean surface temperature, and a relationship between temperature and sea level used to construct sea level rise scenarios. Climate scenarios are constructed from 21 climate models to give an indication of the uncertainty between forcing and response. The analysis shows that there is considerable uncertainty in the impacts associated with a given increase in global mean temperature, due largely to uncertainty in the projected regional change in precipitation. This has important policy implications. There is evidence for some sectors of a non-linear relationship between global mean temperature change and impact, due to the changing relative importance of temperature and precipitation change. In the socio-economic sectors considered here, the relationships are reasonably consistent between socio-economic scenarios if impacts are expressed in proportional terms, but there can be large differences in absolute terms. There are a number of caveats with the approach, including the use of pattern-scaling to construct scenarios, the use of one impacts model per sector, and the sensitivity of the shape of the relationships between forcing and response to the definition of the impact indicator.

\section{Introduction}

There is a very strong policy interest in the impacts of climate change corresponding to different degrees of climate change. The Copenhagen Accord, for example, specifically states the ambition of limiting the increase in global mean temperature to $2{ }^{\circ} \mathrm{C}$ above the pre-industrial value, and the Durban Platform introduces a more stringent aspirational target of $1.5^{\circ} \mathrm{C}$. Setting aside for the moment the challenges in defining, agreeing and delivering emissions pathways that achieve these targets, there is currently little systematic evidence on the impacts that would be incurred at different levels of change in global mean temperature. This is largely because the vast majority of impact assessments are concerned with estimating impacts at a particular time under specific emissions and socio-economic scenarios, rather than the impacts associated with a specific change in temperature. Nevertheless, there have been numerous attempts to characterise the relationship between global temperature change and impacts at global and regional scales. The 'burning embers' diagram (IPCC 2001; Smith et al. 2009) distinguishes five 'reasons for concern' about climate change, and impacts under each with rising global mean temperature are characterised by changes in colour from yellow to red. However, the characterisation of the relationship between global temperature change and impact was based on expert judgement, informed by 'snapshot' impact assessments made under different emissions and socio-economic scenarios. The IPCC's Fourth Assessment Report (IPCC 2007) includes summary diagrams of the global and regional impacts by sector for different amounts of global temperature change, again based on expert judgement. Parry et al. (2001) and Hitz and Smith (2004) both sought to construct relationships between global temperature change and global impact through meta-analyses of existing studies using different emissions scenarios, socioeconomic scenarios and time horizons. Piontek et al. (2013) considered impacts related to water, agriculture, ecosystems, and malaria at different levels of global warming but their focus was on multi-sectoral overlaps, rather than the quantification of climate impact functions per se. They observed that $11 \%$ of the global population was subject to severe impacts in at least two of the four impact sectors at $4{ }^{\circ} \mathrm{C}$.

The relationship between global temperature change and impact depends on the spatial and seasonal patterns of change in relevant climate and sea level variables associated with that temperature change, and on the characteristics of the system being impacted. For socioeconomic systems, these characteristics change over time so the socio-economic impacts of 
a, say, $2{ }^{\circ} \mathrm{C}$ rise in temperature will be different in 2050 and 2080. Impacts on vegetation are affected by changes in the concentration of (particularly) $\mathrm{CO}_{2}$ in the atmosphere, so the relationship between forcing and impact may therefore also be conditional on assumed atmospheric composition. Finally, some systems respond relatively slowly to changes in forcing, so the impacts at $2{ }^{\circ} \mathrm{C}$ for example may actually reflect smaller earlier forcings.

This paper presents relationships between change in global mean temperature and global-scale impact in 2050 across a range of sectors. It combines scenarios for change in global sea level and local climate scaled to match a range of specific prescribed changes in global mean temperature with time-dependent socio-economic scenarios. Impacts are estimated using spatially-explicit impacts models and aggregated to the global scale. The presentation here focuses on one time horizon and one socio-economic scenario (SRES A1b), but the paper also assesses the extent to which socioeconomic assumptions affect the relationship between forcing and impact. The uncertainty in the relationship between forcing and impact due to uncertainty in the spatial pattern of climate change is represented by constructing climate scenarios from 21 different climate models. It is assumed that $\mathrm{CO}_{2}$ concentration in 2050 is $532 \mathrm{ppmv}$ (the SRES A1b value). Note that this is close to the RCP8.5 value (540 ppmv).

The analysis presented in this paper complements two other global-scale assessments using the same suite of impacts and climate models. Arnell et al. (2013a) estimated the global and regional impacts under a set of specific (SRES) emissions scenarios (a more traditional approach to impact assessment), and Arnell et al. (2013b) compared the global and regional impacts under 'business-as-usual' and idealised emissions policies. Other studies (e.g. Fussel et al. (2003), Kleinen and Petschel-Held (2007) and Gerten et al. (2013)) have used a similar approach to construct response functions, but the analysis in this paper uses a wider range of indicators and (compared with Fussel et al. (2003) and Kleinen and Petschel-Held (2007)) characterises uncertainty using a wider range of climate model patterns.

Relationships between the amount of climate forcing and climate change impact can be used not only to provide high-level indications of the potential impacts of different amounts of climate change, but can also be used in regional and global impact assessments where it is not feasible to run detailed, spatially-explicit impacts models. This can be done by combining response functions with global temperature change as predicted under different emissions scenarios by a simple climate model, or by incorporating response functions into integrated assessment models. Economic integrated assessment models (e.g. Boyer and Nordhaus 2000; Tol 2002; Hope 2006) use relationships between temperature and the impacts of climate change expressed in economic terms. These are typically set as mathematical functions of temperature (for example linear, quadratic or stepped), but the shapes of such functions could be informed by 'empirical' relationships based on the application of spatially-explicit impacts models with scenarios representing different amounts of climate change.

\section{Methodology and impact indicators}

\subsection{Introduction}

The basic approach involves running spatially-explicit impacts models with climate and sea level scenarios representing a specific prescribed change in global mean temperature and a socioeconomic scenario representing conditions at a specific time horizon. The relationship between amount of forcing (i.e. global temperature change) and impact for a given socio-economic scenario and time horizon is constructed by repeating the calculations with climate and sea level scenarios representing different changes in global mean temperature. 
The impact indicators are summarised in Table 1, and explained in more detail in Section 2.2. Impacts in 2050 are simulated at a fine spatial resolution $\left(0.5 \times 0.5^{\circ}\right.$ or by coastal segment, average length $85 \mathrm{~km}$ ), and indicators are calculated at the regional and global scales. Only global-scale response functions are reported here (but regional results are presented in Supplementary Material). The period 1961-1990 is used to characterise the 'current' climate, against which climate changes are compared. For comparative purposes, note that the SRES A1b emissions trajectory produces a range in change in global mean surface temperature in 2050 (relative to $1961-1990$ ) of approximately $1.5-2.4{ }^{\circ} \mathrm{C}$ (calculated using a probabilistic version (Lowe et al. 2009) of the MAGICC simple climate model (Meinshausen et al. 2011)), and RCP8.5 produces a change of $1.7-2.9^{\circ} \mathrm{C}$ (IPCC 2013).

Climate scenarios representing spatial and seasonal changes in climate variables associated with specific changes in global mean temperature were constructed by pattern-scaling output from 21 climate models (Section 2.3). Sea level scenarios associated with specific temperature changes were constructed by rescaling a transient sea level rise trajectory (Section 2.4). The socio-economic scenarios used are summarised in Section 2.5.

\subsection{Impact indicators}

The population exposed to change in water stress and the flood-prone population exposed to change in frequency of river flooding are based on 30 years of river flows simulated using the global hydrological model Mac-PDM.09 (Gosling and Arnell 2011; Arnell and Gosling 2013a). A watershed with an average annual runoff less than $1,000 \mathrm{~m}^{3} /$ capita/year is assumed to be exposed to water stress (Gosling and Arnell 2013). A change in exposure is assumed to occur where climate change causes the average annual runoff to change (increase or decrease) greater than the standard deviation due to multi-decadal variability, or where average annual runoff either falls below the $1,000 \mathrm{~m}^{3} /$ capita/year threshold or rises above it. A similar indicator was used by Gerten et al. (2013). Change in exposure to flood hazard is indexed by the number of flood-prone people living in grid cells where the frequency of the baseline 20-year flood doubles or halves (Arnell and Gosling 2013b); the indicator used by Kleinen and Petschel-Held (2007) is similar in principle, but calculated at the major basin rather than grid cell level.

Table 1 Impact indicators

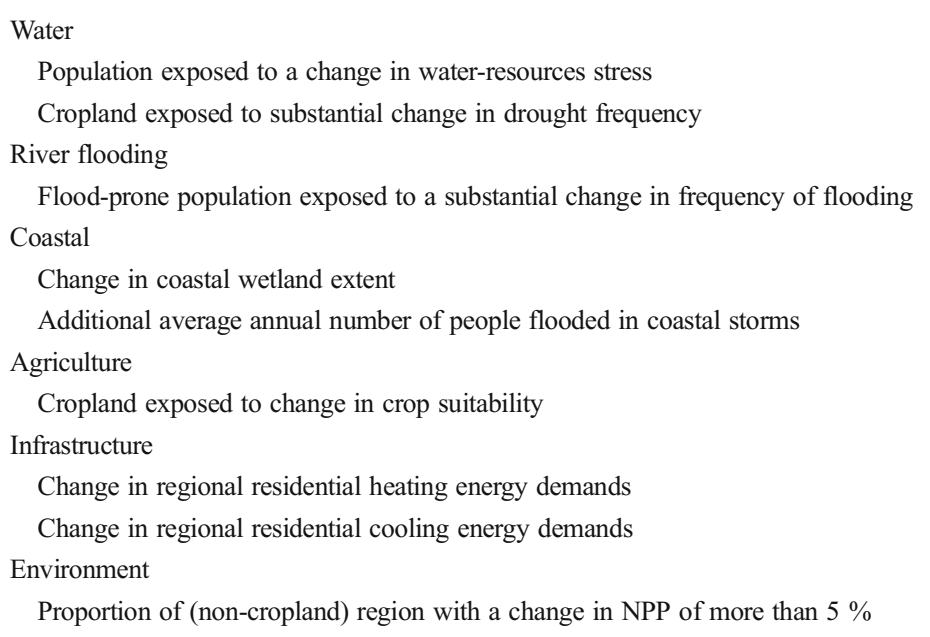


Drought frequency for each cell is estimated by calculating the 12-month standardised precipitation index (SPI: McKee et al. 1993) from the 30-year monthly precipitation time series. A 'drought' is defined as a month with an index of less than -1 , which occurs $15 \%$ of the time in the 1961-1990 baseline. The impacts of changes in drought frequency are indexed by the area of cropland with either a doubling ( $>30 \%)$ or a halving $(<7.5 \%)$ of drought frequency.

The effects of climate change on suitability for cropping are represented by the areas of cropland with changes in a crop suitability index (Ramankutty et al. 2002) of more than $5 \%$. The crop suitability index characterises suitability based on climatic (temperature, and the ratio of actual to potential evaporation) and soil (organic carbon content and $\mathrm{pH}$ ) conditions.

Changes in the number of people flooded in the coastal zone and coastal wetland extent are calculated using the Dynamic Interactive Vulnerability Assessment (DIVA) model (Hinkel and Klein 2009; Vafeidis et al. 2008; Brown et al. 2013), which combines changes in sea level with estimates of vertical land movement to determine local sea level rise and change in the flood frequency curve. It is assumed in this application that the level of coastal protection increases as population and wealth increases in the coastal zone.

Changes in ecosystem characteristics are calculated using the dynamic global vegetation model JULES/IMOGEN (Huntingford et al. 2010). Impacts on terrestrial ecosystems are characterised by the proportion of grid cells in which simulated Net Primary Productivity (NPP) changes by more than $10 \%$; the calculation is made across grid cells with more than $500 \mathrm{~km}^{2}$ of land that is not classified as either cropland or pasture. Ecosystem changes are dependent not only on changes in climate, but also changes in atmospheric $\mathrm{CO}_{2}$ concentration. It is here assumed that $\mathrm{CO}_{2}$ concentrations in 2050 are fixed at 532 ppmv (the SRES Alb projection) for all prescribed changes in temperature. In practice, it is unlikely that such levels of $\mathrm{CO}_{2}$ would be consistent with either very low (< approximately $\left.1{ }^{\circ} \mathrm{C}\right)$ or high $\left(>4{ }^{\circ} \mathrm{C}\right)$ temperature changes. Both Fussel et al. (2003) and Gerten et al. (2013) used different indicators of ecosystem change, and also associated different temperature changes with different $\mathrm{CO}_{2}$ concentrations.

The impacts of climate change in the built environment are indexed by changes in regional domestic heating and cooling energy requirements, estimated using a simplified version of Isaac and van Vuuren (2009) energy demand model. This projects energy requirements from heating and cooling degree days, together with population, household size and global-scale assumptions about heating and cooling technologies and efficiencies.

None of the indicators explicitly incorporate the effects of adaptation. All therefore can be interpreted as representing exposure to the impact of climate change.

\subsection{Climate data and scenarios}

Climate scenarios were constructed (Osborn et al., In prep) by pattern-scaling spatial fields of monthly climate variables from 21 of the climate models in the CMIP3 (Coupled Model Intercomparison Project phase 3) set (Meehl et al. 2007a) to represent different prescribed changes in global mean temperature. A central assumption in the pattern-scaling approach is therefore that the relationship between local change in each climate variable and global temperature change is one-directional and (perhaps after transformation) linear. This is reasonable (at least for temperature and precipitation) for moderate amounts of global mean temperature change (Mitchell 2003; Neelin et al. 2006), but may not hold for high temperature changes which may be associated with step changes in climate regime in certain locations. Also, there is some evidence of non-linear relationships between global mean temperature in some tropical regions (Good et al. 2012), and the presence of strong regionally-specific 
forcings (e.g. through aerosols) may complicate relationships. The pattern-scaled climate scenarios are therefore to be regarded as indicative only.

All 21 climate models are here assumed equally plausible, but note that they do not represent a set of 21 independent models. Impacts are calculated under all 21 climate models individually. The ensemble mean climate scenario is not used, because averaging model climate projections leads to a loss of signal where projected changes are of different directions, underestimates spatial variability in change, and hides the relationships between different indicators of impact. Also, the distribution of models in model or parameter space is unclear (Knutti et al. 2010). One climate model (HadCM3) is highlighted in the figures presented here in order to illustrate the relationships between indicators and (in the Supplementary Material) impacts in different regions. This model was selected as the indicator simply because it has been used previously in many impact assessments.

The pattern-scaled climate scenarios were interpolated statistically from the native climate model resolution (typically of the order of $3 \times 3^{\circ}$ ) to $0.5 \times 0.5^{\circ}$, and 30 -year time series representing climates corresponding to defined changes in global mean temperature above 1961-1990 were constructed by applying the scenarios to the CRU TS3.1 observed $0.5 \times 0.5^{\circ} 1961-1990$ climatology (Harris et al. 2013). Terrestrial ecosystem impacts are dependent on the history of change in climate over time. Prescribed transient scenarios were constructed by scaling the trajectory of temperature change under Alb emissions to match defined temperature changes (e.g. $2^{\circ} \mathrm{C}$ ) in 2050. The impacts in 2050 for this indicator therefore represent the cumulative effects experienced by the time temperatures reach the prescribed increase in 2050 .

\subsection{Sea level scenarios}

Sea level scenarios representing different changes in temperature in 2050 were constructed in a different way to the climate scenarios. First, a set of sea level rise trajectories was derived from the trajectory of sea level rise under A1b, scaled to correspond to a range of increases in global mean sea level (by 2050, these ranged between 6 and $48 \mathrm{~cm}$ above the 1990 level, compared with the original A1b value of $18 \mathrm{~cm}$ ). Second, estimates of the change in global mean temperature in 2050 associated with each incremental change in sea level in 2050 were derived using relationships between temperature and sea level constructed for 15 climate models. These relationships were constructed by using the MAGICC 4.2 simple climate model to estimate the thermal expansion component of sea level rise with increasing temperature (with parameters tuned to the 15 different climate models), and estimating the contribution from melting ice sheets and glaciers using the same methodology as applied in Meehl et al. (2007b). The temperatures associated with given sea level rises are shown in Supplementary Figure 1, which also shows the relationships between temperature and sea level rise.

\subsection{Socio-economic scenarios}

Future population and gross domestic product were taken from the IMAGE v2.3 representation of the A1b, A2 and B2 storylines (van Vuuren et al. 2007). The population living in inland river floodplains was estimated by combining the high-spatial resolution CIESIN GRUMP data set (CIESIN 2004) with 5' flood-prone areas defined in the UN PREVIEW Global Risk Data Platform (preview.grid.unep.ch); it is assumed that the proportion of population living in flood-prone areas within each $0.5 \times 0.5^{\circ}$ grid cell or coastal segment does not change over time. Cropland extent was taken from the Ramankutty et al. (2008) global cropland data base, and assumed not to change over time. 


\section{Results}

\subsection{Indicators of exposure in the absence of climate change}

Table 2 summarises a range of 'exposure' measures in 2050, under the Alb socio-economic scenario, assuming that climate and sea level remain at 1961-1990 levels; year 2000 values provide a context for change by 2050. In 2050, global population has increased to around 8.2 billion Approximately 3 billion people live in watersheds with less than $1,000 \mathrm{~m}^{3} / \mathrm{capita} /$ year-twice the 2000 value. Around 840 million people live in river floodplains, and around 600 thousand people a year are flooded in coastal floods. This last figure is lower than in 2000, primarily because coastal flood protection standards are assumed to increase over time as population and wealth increases. Heat energy demands vary with population, but because cool energy demands are also a function of wealth, these continue to increase through the $21 \mathrm{st}$ century; they increase from $3 \%$ of total heating and cooling energy demands in 2000 , to $16 \%$ in 2050. Coastal wetland extent declines slightly because of regional land movements.

The majority of people already exposed to water resources stress (approximately $74 \%$ of the global total in 2000) live in south Asia and China, and these two regions also account in 2000 for around $62 \%$ of river flood-prone people and $43 \%$ of the people flooded in coastal floods. Most of the rest of the global total of people exposed to river and coastal floods are in south East Asia. The simulated increases in residential heating energy demand are greatest in East Asia (especially China) and south Asia, whilst the largest increases in residential cooling energy demand are simulated in south, south east and East Asia.

\subsection{The relationship between forcing and impact in 2050}

Figure 1 shows the relationship between climate forcing (global mean temperature increase above the 1961-1990 mean) and global-scale impact in 2050, for the indicators shown in Table 1 . The functions are shown separately for the 21 climate models (19 for change in NPP, and 15 for the coastal indicators). Similar functions for regional-scale impacts are presented in Supplementary Figure 2 (and data are available in online supplementary material).

There is considerable uncertainty in the relationship between forcing and impact between the climate models for most indicators, and estimated impacts at any temperature change are therefore uncertain. For example, at $2{ }^{\circ} \mathrm{C}$ crop suitability declines across between 20 and $60 \%$ of cropland, between 10 and $40 \%$ of global population sees an increased exposure to water resources stress, and between 5 and $50 \%$ of people in river floodplains are exposed to a

Table 2 Global-scale exposure measures in the absence of climate change in 2000 and 2050, under an A1 socioeconomic scenario

\begin{tabular}{lll}
\hline & 2000 & 2050 \\
\hline Population (m) & 6,122 & 8,196 \\
Water-stressed population (m) & 1,555 & 3,064 \\
Population exposed to river flooding (m) & 637 & 843 \\
Cropland $\left(\mathrm{k} \mathrm{km}^{2}\right.$ ) & 14,447 & 14,447 \\
Coastal wetland $\left(\mathrm{k} \mathrm{km}^{2}\right)$ & 858 & 854 \\
Average annual number of people flooded in coastal floods (k/year) & 3,437 & 606 \\
Regional heat energy demand (PJ) & 30,447 & 42,662 \\
Regional cool energy demand (PJ) & 857 & 7,259 \\
\hline
\end{tabular}




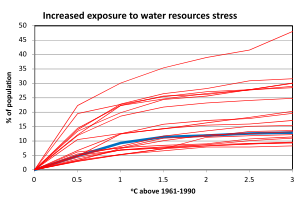

Decline in suitability for cropping
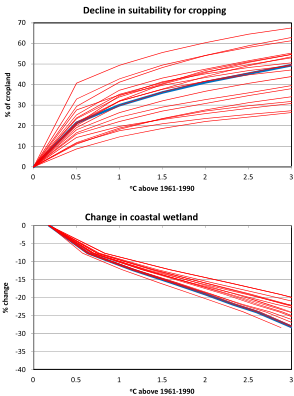

crease in NPP

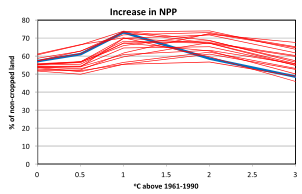

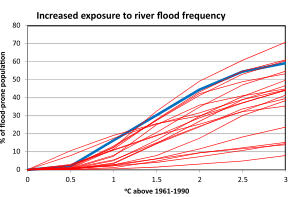
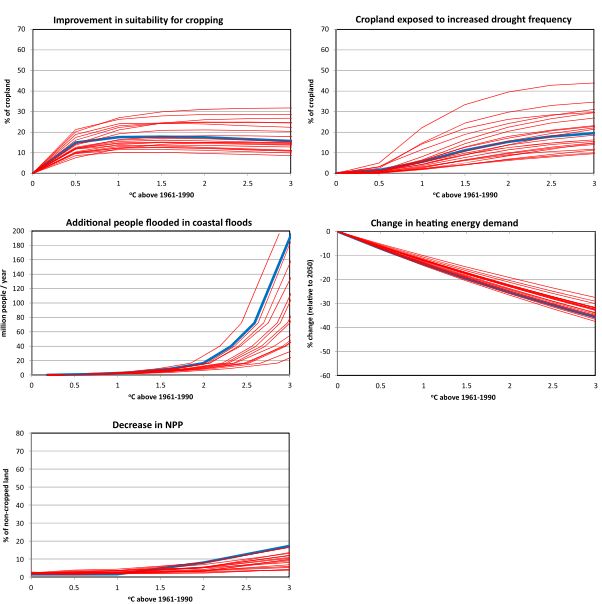
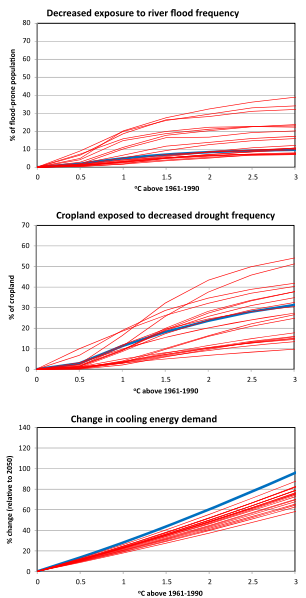

Fig. 1 Relationship between global temperature increase above 1961-1990 and global-scale impact indicators, under an A1 socio-economic and emissions scenario in 2050 . Add $0.3{ }^{\circ} \mathrm{C}$ to estimate change in global mean temperature relative to pre-industrial. 1,2 and $3{ }^{\circ} \mathrm{C}$ above $1961-1990$ correspond to $1.3,2.3$ and $3.3{ }^{\circ} \mathrm{C}$ above pre-industrial. The relationship with the HadCM3 climate model pattern is highlighted

doubling of flood frequency. This is primarily due to differences in the spatial pattern of change in precipitation between the climate models. There is less uncertainty in the relationship between forcing and energy demands because there is less difference between models in projected patterns of temperature change, although even for projected residential cooling demands there is a range at $2{ }^{\circ} \mathrm{C}$ of increases between 40 and $60 \%$. There is also less uncertainty in coastal impacts; an additional 8-30 million people are flooded each year with a $2{ }^{\circ} \mathrm{C}$ rise in temperature. Note that the changes with the indicative HadCM3 pattern are close to the middle of the range for some indicators, but at the extreme of the range for others (it produces the highest increase in cooling energy demands, for example). Also, the HadCM3 functions illustrate relationships between indicators. The HadCM3 pattern, for example, results in relatively low estimates for increased exposure to water resources stress and reductions in flooding, but high estimates for increased exposure to river flooding and apparent reductions in water stress; it has a large decrease in heating demand, and a large increase in cooling demand.

Many of the relationships between forcing and impact on exposure to water resources stress, change in river flood and drought frequency, and change in crop suitability, tend to asymptote towards an apparent limit, with the limit and the point at which the change levels off varying between the climate model patterns. This occurs because these indicators are based on thresholds - for example a 'significant' change in runoff or a $5 \%$ change in crop suitabilityand once this threshold is crossed it clearly cannot be crossed again. The coastal and energy indicators, in contrast, show change in 'volume', and they increase consistently with increase in global mean temperature. The additional numbers of people flooded in coastal floods increases particularly substantially beyond a $2{ }^{\circ} \mathrm{C}$ rise in temperature, but the heating and cooling energy demands increase more linearly with temperature. 
For most of the climate model patterns, the proportion of cropland with an increase in suitability increases as temperature increases to approximately $1-2{ }^{\circ} \mathrm{C}$ above $1961-1990$, but decreases slightly thereafter. This is because in some regions - primarily in high latitude
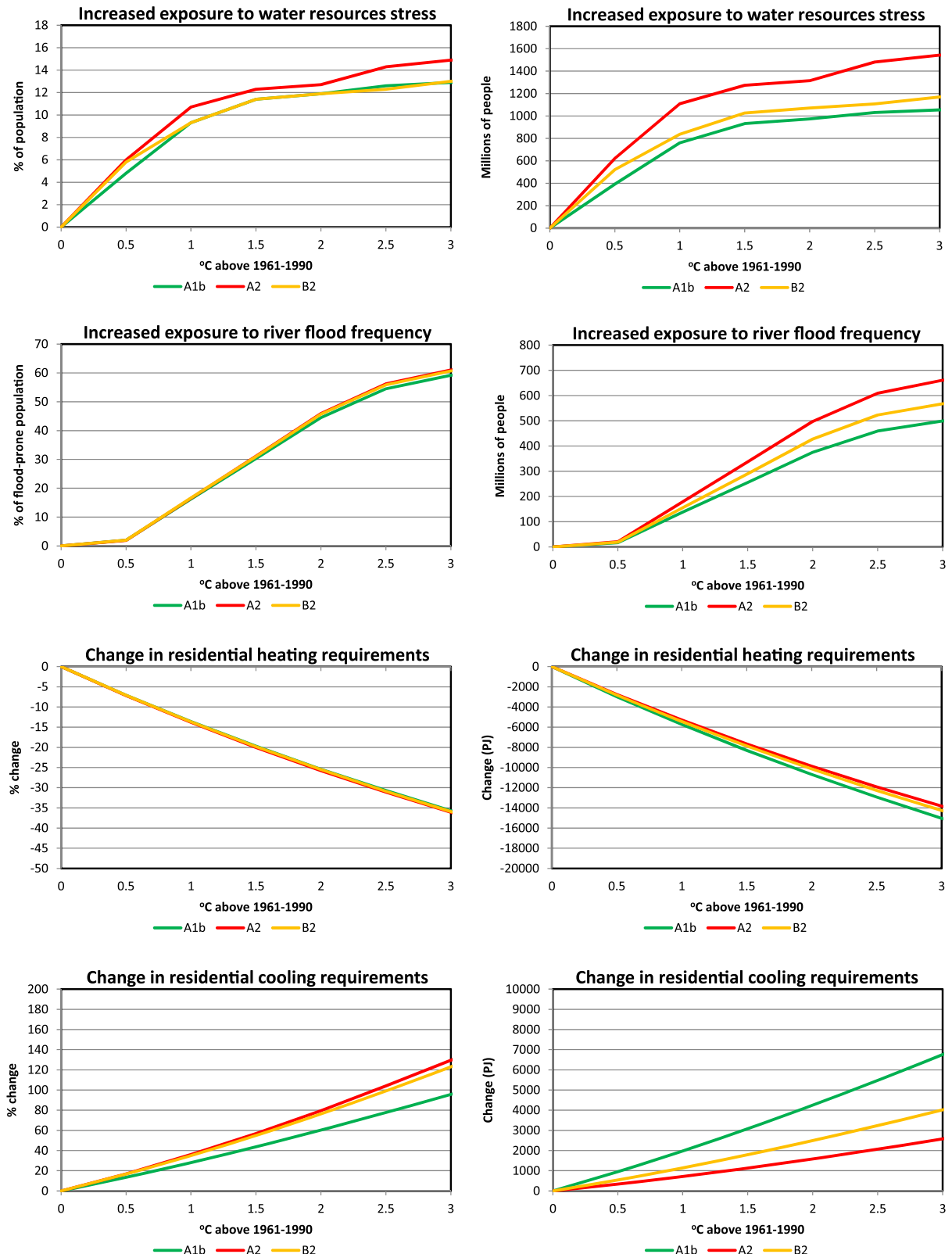

Fig. 2 Effect of socio-economic scenario on the relationship between global mean temperature change and impacts on water resources stress, exposure to change in river flood frequency, and residential energy requirements. HadCM3 climate model pattern. Add $0.3{ }^{\circ} \mathrm{C}$ to estimate change in global mean temperature relative to pre-industrial. 1,2 and $3{ }^{\circ} \mathrm{C}$ above $1961-1990$ correspond to $1.3,2.3$ and $3.3^{\circ} \mathrm{C}$ above pre-industrial 
eastern Europe and Canada - as temperatures increase, the beneficial effects of increased temperature are increasingly offset by the adverse effects of lower ratios of actual to potential evaporation.

The functions relating temperature change in 2050 to change in NPP assume a $\mathrm{CO}_{2}$ concentration of 532 ppmv. With just a change in $\mathrm{CO}_{2}$ from $370 \mathrm{ppmv}$ and no change in climate, between 52 and $62 \%$ of the (non-cropped) land area sees an increase in NPP of more than $10 \%$. An increase in global mean temperature of up to $1{ }^{\circ} \mathrm{C}$ tends to lead to a greater area with an increase in NPP, but thereafter the area with increasing NPP begins to fall. The temperature effects are, however, small at the global scale, and the area with an increase in NPP in 2050 is most strongly affected by increasing $\mathrm{CO}_{2}$ concentrations. In contrast, the area with a decrease in NPP-whilst considerably smaller than the area with an increase - is more sensitive to change in climate.

Regional functions are shown in Supplementary Figure 2. They show considerable regional diversity in the shape of the functions and the amount of uncertainty, and the highlighted HadCM3 functions illustrate relationships between changes in different regions.

\subsection{Sensitivity to assumed socio-economic scenario}

Figure 2 shows the effect of three different socio-economic assumptions (SRES A1b, A2 and B2) on the relationship between forcing and impacts on exposure to water resources stress and change in river flood frequency, and heating and cooling demands, in 2050.

For both the hydrological measures, the relationships are very insensitive to the assumed socio-economic scenario when impacts are expressed in proportional terms. In absolute terms, the impacts of a given increase in temperature, however, can be very different between socioeconomic scenarios.

Changes in residential cooling demands are much more sensitive to socio-economic scenario, and this is largely because the regional distribution of baseline demands is different under the three scenarios considered here. Simulated demands are much higher in south east and east Asia under A1b than the other two scenarios, and are dependent on both population and GDP.

\section{Conclusions}

This paper has presented global-scale relationships between the amount of climate change, as characterised by global mean temperature, and a series of indicators of climate change impact. Such relationships can be used to quantify previouslyqualitative schematics representing the impacts of climate change, can be used directly to rapidly estimate impacts at any specified global mean temperature change, and can inform the shapes of relationships between forcing and impact used in integrated assessment models.

There are a number of caveats with the analysis. The construction of the relationships relies on the use of a simple pattern-scaling approach to produce climate scenarios representing defined changes in global mean temperature; more sophisticated approaches could be developed to account for non-linear responses, regionallysignificant forcings and step changes. The analysis here uses only one impacts model per sector. Other impacts models could result in differently-shaped relationships; the effect of impact model uncertainty is currently being explored through the ISI-MIP 
initiative (www.isi-mip.org). Note that the relationships between global mean temperature change and increased exposure to water resources stress here are similar in principle - although slightly different quantitatively - to those presented by Gerten et al. (2013). The relationships presented here assume each of the 21 climate models considered is equally plausible. In some cases, the uncertainty range is very much influenced by a single outlier model - but it is not always the same model that produces an outlier. The range is based on CMIP3 climate models. The CMIP5 climate model ensemble produces a broadly similar range in spatial patterns of change in climate by the end of the 21st century (Knutti and Sedlacek 2013), so it is unlikely that relationships based on CMIP5 models would show substantially different ranges; this has been demonstrated for water stress impacts (Gosling and Arnell 2013). The relationships produced here assume that $\mathrm{CO}_{2}$ concentrations at a given time horizon are known (here following the SRES Alb trajectory and approximating closely RCP8.5). Uncertainty bands could be constructed by using a range of plausible $\mathrm{CO}_{2}$ concentrations at each time period. Finally, the shape of the relationship between forcing and response can be dependent on the precise definition of the impact indicator. Many of the indicators used here are based on the exceedance of thresholds, and these can produce response functions which appear to asymptote.

Recognising these caveats, it is possible to draw a number of conclusions. For most indicators, there is considerable uncertainty (at global and regional scales) in the impacts associated with a defined change in temperature. This is largely due to differences between climate models in the projected spatial pattern of change in precipitation, although there is some uncertainty associated the projected patterns of temperature change. The range between climate models varies between regions, and where models are more consistent in their projections of change the range is obviously lower. A clear implication is that it is currently very difficult to estimate with precision the impacts at any defined change in global mean temperature, and that the estimated range will depend on the ensemble of climate models considered. There is also evidence in some sectors and regions of non-linear responses of impact indicators to changes in global mean temperature. In one of the examples here, parts of the world experience an improvement in crop suitability for modest increases in temperature, but as temperature rises suitability begins to decline.

The ranges in response shown for each indicator are not independent; a future world with a large increase in the area with increased exposure to water resources stress, for example, may not plausibly have a large increase in exposure to river flood hazard. This has two implications. First, if it is possible to produce some global aggregated impact metric across sectors (for example by converting all impacts into dollars), then the range in that metric will not be as large as the sum of all the ranges for the individual impact indicators. Second, if the relationships here are to be used in a probabilistic uncertainty analysis of the impacts of climate change, then it is necessary to take into account the correlation between impact indicators. It is not appropriate to mix and match the highest and lowest impacts for each sector.

Acknowledgments The research presented in this paper was conducted as part of the QUEST-GSI project, funded by the UK Natural Environment Research Council (NERC) under the QUEST programme (grant number NE/E001890/1). For the climate change and sea level rise patterns we acknowledge the international modelling groups for providing their data for analysis, the Program for Climate Model Diagnosis and Intercomparison (PCMDI) for collecting and archiving the model data, the JSC/CLIVAR Working Group on Coupled Modelling (WGCM) and their Coupled Model Intercomparison Project (CMIP) and Climate Simulation Panel for organising the model data analysis activity, and the IPCC WG1 TSU for technical support. The IPCC Data Archive at Lawrence Livermore National Laboratory is supported by the Office of Science, US Department of Energy. The authors thank the referees for their constructive comments. The regional and global functions are available in online supplementary material. 
Open Access This article is distributed under the terms of the Creative Commons Attribution License which permits any use, distribution, and reproduction in any medium, provided the original author(s) and the source are credited.

\section{References}

Arnell NW, Gosling SN (2013a) The impacts of climate change on river flow regimes at the global scale. J Hydrol 486:351-364

Arnell NW, Gosling SN (2013b) The impacts of climate change on river flood risk at the global scale. Clim Chang under review

Arnell NW et al (2013a) A global-scale, multi-sectoral regional climate change risk assessment. Clim Chang under review

Arnell NW et al (2013b) A global assessment of the effects of climate policy on the impacts of climate change. Nat Clim Chang 3:512-519

Boyer J, Nordhaus WD (2000) Warming the world: economic models of global warming. MIT Press, Cambridge

Brown S, Nicholls RJ, Lowe JA, Hinkel J (2013) Spatial variations of sea-level rise and impacts: an application of DIVA. Clim Chang. doi:10.1007/s10584-013-0925-y

Center for International Earth Science Information Network (CIESIN) CU; (IFPRI); IFPRI, Bank; TW; (CIAT) CIdAT (2004) Global Rural-Urban Mapping Project (GRUMP), alpha version: population grids. Socioeconomic Data and Applications Center (SEDAC), Columbia University. Available at http://sedac. ciesin.columbia.edu/gpw. (1 April 2011), Palisades: NY

Fussel HM et al (2003) Climate impact response functions as impact tools in the tolerable windows approach. Clim Chang 56:91-117

Gerten D et al (2013) Asynchronous exposure to global warming: freshwater resources and terrestrial ecosystems. Environ Res Lett 8:034032

Good P et al (2012) A step-response approach for predicting and understanding non-linear precipitation changes. Clim Dyn 39:2789-2803

Gosling SN, Arnell NW (2011) Simulating current global river runoff with a global hydrological model: model revisions, validation, and sensitivity analysis. Hydrol Process 25:1129-1145

Gosling SN, Arnell NW (2013) A global assessment of the impact of climate change on water scarcity. Clim Chang. doi:10.1007/s10584-013-0853-x

Harris I, Jones PD, Osborn TJ, Lister DH (2013) Updated high-resolution grids of monthly climatic observations - the CRU TS3.10 data set. Int J Climatol. doi:10.1002/joc.3711

Hinkel J, Klein RJT (2009) Integrating knowledge to assess coastal vulnerability to sea-level rise: the development of the DIVA tool. Glob Environ Chang Hum Policy Dimens 19:384-395

Hitz S, Smith J (2004) Estimating global impacts from climate change. Glob Environ Chang Hum Policy Dimens $14: 201-218$

Hope CW (2006) The marginal impacts of CO2, CH4 and SF6 emissions. Clim Pol 6:537-544

Huntingford $\mathrm{C}$ et al (2010) IMOGEN: an intermediate complexity model to evaluate terrestrial impacts of a changing climate. Geosci Model Dev 3:679-687

IPCC (2001) Summary for policymakers. Climate change 2001: impacts, adaptation, and vulnerability. contribution of working group ii to the third assessment report of the intergovernmental panel on climate change. Cambridge University Press, Cambridge

IPCC (2007) Summary for policymakers. In: Parry ML et al (eds) Climate change 2007: impacts, adaptation and vulnerability. Contribution of working group II to the fourth assessment report of the intergovernmental panel on climate change. Cambridge University Press, Cambridge, pp 7-22

IPCC (2013) Summary for Policymakes. Climate Change 2013: The Science of Climate Change. Contribution of Working Group I to the Fifth Assessment Report of the Intergovernmental Panel on Climate Change

Isaac M, van Vuuren DP (2009) Modeling global residential sector energy demand for heating and air conditioning in the context of climate change. Energy Policy 37:507-521

Kleinen T, Petschel-Held G (2007) Integrated assessment of changes in flooding probabilities due to climate change. Clim Chang 81:283-312

Knutti R, Sedlacek J (2013) Robustness and uncertainties in the new CMIP5 climate model projections. Nat Clim Chang 3:369-373

Knutti R et al (2010) Challenges in combining projections from multiple climate models. J Clim 23:2739-2758

Lowe JA et al (2009) How difficult is it to recover from dangerous levels of global warming? Environ Res Lett 4. doi:10.1088/1748-9326/4/1/014012 
McKee TB, Doesken NJ, Kliest J (1993) The relationship of drought frequency and duration to time scales. In: Proceedings of the 8th conference on applied climatology. American Meteorological Society, Boston, pp. 179-184

Meehl GA et al (2007a) The WCRP CMIP3 multimodel dataset - a new era in climate change research. Bull Am Meteorol Soc 88:1383

Meehl GA et al (2007b) Global climate projections. In: Solomon S (ed) Climate change 2007: the physical science basis. Contribution of working group 1 to the fourth assessment report of the intergovernmental panel on climate change. Cambridge University Press, Cambridge

Meinshausen M, Raper SCB, Wigley TML (2011) Emulating coupled atmosphere-ocean and carbon cycle models with a simpler model, MAGICC6-Part 1: model description and calibration. Atmos Chem Phys 11: 1417-1456

Mitchell TD (2003) Pattern scaling - an examination of the accuracy of the technique for describing future climates. Clim Chang 60:217-242

Neelin JD et al (2006) Tropical drying trends in global warming models and observations. Proc Natl Acad Sci U S A 103:6110-6115

Parry ML et al (2001) Millions at risk: defining critical climate change threats and targets. Glob Environ Chang 11:1-3

Piontek F et al (2013) Multisectoral climate impact hotspots in a warming world. Proc Natl Acad Sci. doi:10. 1073/pnas. 1222471110

Ramankutty N et al (2008) Farming the planet: 1. Geographic distribution of global agricultural lands in the year 2000. Glob Biogeochem Cycles 22, Gb1003

Ramankutty N et al (2002) The global distribution of cultivable lands: current patterns and sensitivity to possible climate change. Glob Ecol Biogeogr 11:377-392

Smith JB et al (2009) Assessing dangerous climate change through an update of the Intergovernmental Panel on Climate Change (IPCC) "reasons for concern". Proc Natl Acad Sci U S A 106:4133-4137

Tol RSJ (2002) Welfare specifications and optimal control of climate change: an application of FUND. Energy Econ 24:367-376

Vafeidis AT et al (2008) A new global coastal database for impact and vulnerability analysis to sea-level rise. J Coast Res 24:917-924

van Vuuren DP et al (2007) Stabilizing greenhouse gas concentrations at low levels: an assessment of reduction strategies and costs. Clim Chang 81:119-159 